\title{
Effects of oxygen concentration on in vitro maturation of canine oocytes in a chemically defined serum-free medium
}

\author{
Mazdak Salavati ${ }^{1,4}$, Fataneh Ghafari ${ }^{2}$, Tiantian Zhang $^{3}$ and Ali A Fouladi-Nashta ${ }^{4}$ \\ ${ }^{1}$ Institute of Biomedical and Environmental Science and Technology, University of Bedfordshire, Luton, Bedford LU2 \\ $8 D L, U K,{ }^{2}$ Centre for Reproductive Medicine, Walsgrave University Hospital, Coventry CV2 2DX, UK, ${ }^{3}$ School of \\ Applied Sciences, Bournemouth University, Poole BH12 5BB, UK and ${ }^{4}$ Reproduction, Genes and Development \\ Group, Royal Veterinary College, Hawkshead Campus, Hatfield AL9 7TA, UK
}

Correspondence should be addressed to A A Fouladi-Nashta; Email: afouladi@rvc.ac.uk

\begin{abstract}
Canine oocytes require an extended period of culture $(72 \mathrm{~h})$ in vitro for nuclear maturation to the metaphase II stage, which also results in high degeneration. Canine cumulus oocyte complexes were isolated by slicing from ovaries collected after ovariohysterectomy and cultured in serum-free synthetic oviductal fluid incubated at low $(5 \%)$ or high $(\mathbf{2 0} \%)$ oxygen levels. Changes in oocyte nuclear maturation rates, $\mathrm{H}_{2} \mathrm{O}_{2}$ levels within the oocytes and mRNAs of reactive oxygen species inhibitory genes superoxide dismutase 1 and 2 (SOD1 and 2), glutathione reductase (GSR), glutathione peroxidase (GPX1), and catalase (CAT) were quantified. Higher meiotic resumption from germinal vesicle breakdown up to $\mathrm{MII}$ was observed in low $\mathrm{O}_{2}(\mathbf{4 1 . 8} \pm \mathbf{1 3 . 1} \%)$ compared to high $\mathrm{O}_{2}(15.8 \pm 8.2 \%)$ $(P=0.014)$ after $52 \mathrm{~h}$ of culture $(n=112)$. Extension of the culture period up to $84 \mathrm{~h}$ at low $\mathrm{O}_{2}(n=457$ oocytes $)$ produced the highest meiotic resumption at $72 \mathrm{~h}(64.1 \pm 6.0 \% ; P=0.008)$, compared with $52 \mathrm{~h}$. Oocytes $(n=110)$ cultured in high $\mathrm{O}_{2}$ contained higher levels of peroxidase measured using the $2^{\prime}, 7^{\prime}$-dichlorodihydrofluorescein diacetate fluorescence assay after $72 \mathrm{~h}$ of culture compared with low $\mathrm{O}_{2}(P=0.004)$. High $\mathrm{O}_{2}$-cultured oocytes also showed higher amounts of SOD1, SOD2, GSR, GPX1, and CAT mRNA. Vitamin E in high oxygen level was able to decrease degeneration $(P=0.008)$ but had no improving effect on percentage of oocytes in MII. These results for the first time showed that low oxygen gas composition improves nuclear maturation rates and alleviates the oxidative stress for canine oocytes during in vitro maturation.

Reproduction (2012) 144 547-556
\end{abstract}

\section{Introduction}

Dogs have been the most popular companion animals in the history of mankind and have always been part of the social and personal activities of modern human life. Despite all efforts, due to its unique features, a successful system for in vitro maturation (IVM) and IVF could not be established for canid family (Songsasen \& Wildt 2007, Rodrigues \& Rodrigues 2010). In contrast to the majority of mammals, canine oocytes are ovulated at the prophase of the first meiotic division (germinal vesicle, $\mathrm{GV}$ ) and complete the maturation process to metaphase II stage (MII) 48-72 h after ovulation in the oviduct (Hewitt \& England 1999, De los Reyes et al. 2011). High degeneration ( $>50 \%$ ) and very low MII maturation rates $(16.2 \pm 4.2 \%$ ) (Luvoni et al. 2005, Rodrigues \& Rodrigues 2010) are the main features of current IVM in the dog.

Dog oocytes contain abundant lipid droplets that occupy $80-90 \%$ of the visible ooplasm surface (Guraya 1965, Tesoriero 1982, Songsasen et al. 2009). This may reflect the importance of energy supply during the prolonged period of oviductal travel and the maternal zygotic transition period (Guraya 1965, Luvoni et al. 2005, Lopes et al. 2010). However, presence of these abundant lipid droplets in ooplasm has an impeccable influence on predisposition of cumulus oocyte complexes (COCs) to oxidative stress by reactive oxygen species (ROS; Wakefield et al. 2008, Whitaker \& Knight 2008, Tao et al. 2010). Oxygen concentration during the IVM culture period can contribute to the extent and velocity of this oxidative stress of which oocyte nuclear and cytoplasmic maturation and development pattern may perturb (Kim et al. 2007, Whitaker \& Knight 2008).

Glutathione $(\mathrm{GSH})$ is the main non-enzymatic cellular defense mechanisms against ROS and other free radicals (Guerin et al. 2001, Menezo et al. 2010). GSH becomes a substrate of glutathione peroxidase (GPX) in alliance with catalase (CAT), which degrades hydrogen peroxide $\left(\mathrm{H}_{2} \mathrm{O}_{2}\right)$ to water and oxygen (Whitaker \& Knight 2008). $\mathrm{H}_{2} \mathrm{O}_{2}$ itself is the resulting product in neutralization of ROS by superoxide dismutases (SOD) (cytosolic SOD = $\mathrm{Cu}-\mathrm{Zn}$ SOD1, mitochondrial SOD = Mn-SOD2) (Guerin et al. 2001). In order to recover GSH, oocytes use 
another enzyme, glutathione reductase (GSR), to reduce the GS-SG (oxidized form of GSH) back to GSH (Guerin et al. 2001). Because of lower levels of GSH within in vitro matured canine oocytes $(<8 \mathrm{pMol} /$ oocyte $)$ in comparison with in vivo (19.2 pMol/oocyte) (Kim et al. 2007), high levels of $\mathrm{H}_{2} \mathrm{O}_{2}$ and ROS within COCs during IVM can severely impair maturation and increase degeneration rates (Whitaker \& Knight 2008). These studies showed that the $\mathrm{H}_{2} \mathrm{O}_{2}$ level in oocytes is a good indication of oxidative stress.

High oxygen level has detrimental effects on cumulus cell survival (Silva et al. 2009), which influences expansion during oocyte maturation in vitro. In the majority of IVM techniques in domestic animals, cumulus cell expansion and nuclear maturation are concomitant phenomena during the culture period. In other words, expansion of cumulus cells could be a good indicator of the right conditions for nuclear maturation of oocytes within the IVM process (Chen et al. 1990, Qian et al. 2003). In canine oocytes, the relationship between cumulus expansion and nuclear maturation is quite controversial (Otoi et al. 2007, Chebrout et al. 2009, Reynaud et al. 2009), and there have been counterintuitive interpretations for cumulus expansion in canine IVM (Reynaud et al. 2005, 2006, Lee et al. 2007a, Chastant-Maillard et al. 2010). In vivo, expansion of cumulus cells may not concomitant with meiotic resumption as the maturation occurs after ovulation while the expansion initiation time is not clear (Reynaud et al. 2009). In vitro, extensive mucification of cumulus cells occurred only in the presence of canine serum in the maturation media (Lopes et al. 2011). The credibility of cumulus expansion as a reliable indicator of oocyte maturation is to be further elucidated. In addition, due to entrapment of villi of the two or three most inner layers of cumulus cells inside the zona pellucida (ZP; Blackmore et al. 2004, De los Reyes et al. 2009), it is difficult to denude the oocytes for assessment of nuclear maturation or manipulation for other assisted reproduction techniques.

Vitamin $\mathrm{E}$ ( $\boldsymbol{\alpha}$-tocopherol) as a lipid-soluble antioxidant has been proven to have beneficial effects on oocyte maturation and embryo development in pigs (Tao et al. 2010) and alleviates the degeneration rates of bovine and ovine oocytes (Dalvit et al. 2005, Natarajan et al. 2010). This study investigated the impact of oxidative stress on oocyte nuclear maturation and degeneration. Changes in $\mathrm{H}_{2} \mathrm{O}_{2}$ content of oocytes cultured in two oxygen levels were analyzed, and the protective role of an antioxidant (vitamin E) was investigated in pursuit of oxidative stress alleviation and improvement of cumulus cell expansion and oocyte nuclear maturation rates.

\section{Results}

\section{Cumulus cell expansion and oxygen concentration}

Expansion of cumulus cells was assessed in COCs cultured under low- or high-oxygen conditions. No full mucification was observed throughout IVM in either group (absence of extracellular matrix cloud) at $52 \mathrm{~h}$ $(0.0 \%$ full expansion in both groups; not expanded oocytes $97.1 \pm 1.6 \%$ in low $\mathrm{O}_{2}$, and $95.0 \pm 2.7 \%$ in high $\left.\mathrm{O}_{2}(P>0.05)\right)$. However, after $52 \mathrm{~h}$, limited numbers of cumulus cells were disintegrated from the COCs, with higher disintegration in COCs cultured in the highoxygen incubator $\left(5.0 \pm 2.7 \%\right.$ in high $\mathrm{O}_{2}$ vs $2.9 \pm 1.6 \%$ in low $\left.\mathrm{O}_{2} ;(P>0.05)\right)$. Moreover, in high-oxygen culture, disintegrated cells were less attached to the culture dish (Fig. 1).
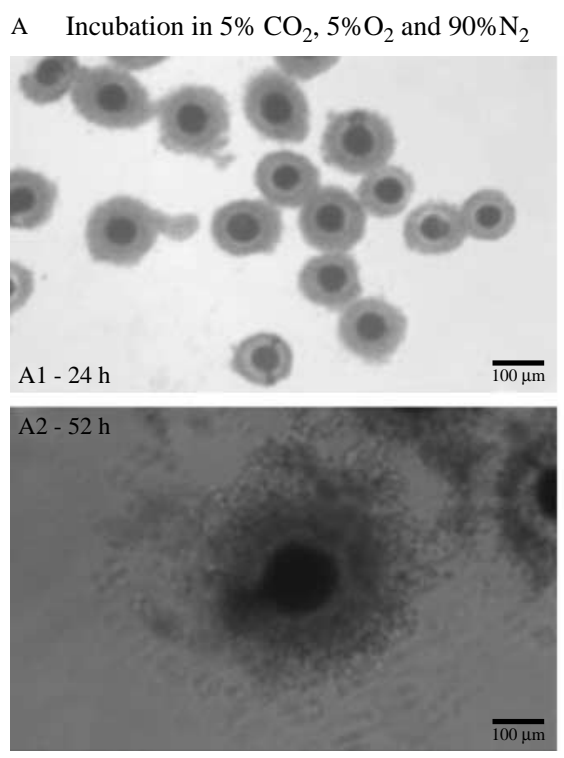
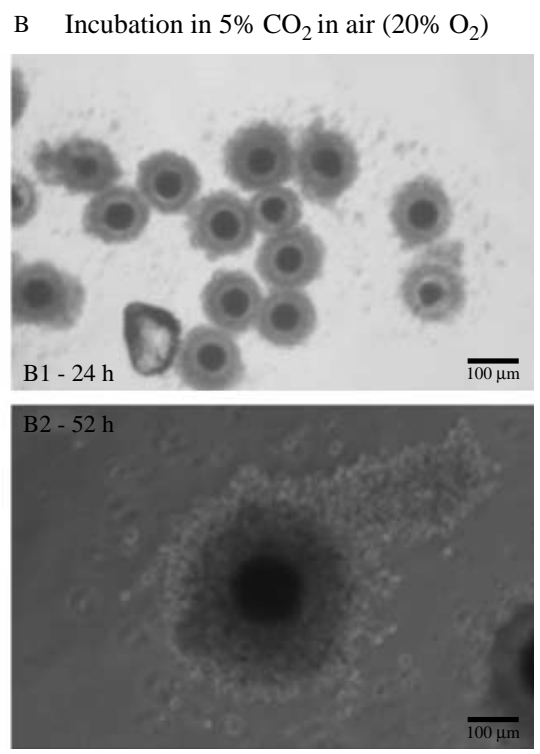

Figure 1 Effect of oxygen level during oocyte culture on cumulus expansion of canine oocytes at 24 and $52 \mathrm{~h}$. Canine oocytes cultured in low (A) or high (B) levels of oxygen (5 vs $20 \%$ ).

Photographs were taken with light field optics to visualize cumulus expansion pattern (A1 and $\mathrm{B} 1=$ oocytes at $24 \mathrm{~h}$ of culture $(4 \times$ objective $))$, (A2 and B2 $=$ oocytes at $52 \mathrm{~h}$ of culture $(10 \times$ objective)). 
Table 1 Effect of oxygen concentration during oocyte culture on nuclear maturation of canine oocytes. Table shows distribution of oocytes in different stages of meiotic division. Meiotic resumption of oocytes (total number of oocytes between GVBD and MII) was significantly higher in low $\mathrm{O}_{2}$ condition.

\begin{tabular}{|c|c|c|c|c|c|c|c|c|c|}
\hline & \multicolumn{7}{|c|}{ Percentage of oocytes (average \pm S.E.M.) in 52-h oxygen comparison } & \multirow{2}{*}{$\begin{array}{c}\text { Meiotic } \\
\text { resumption } \\
\text { (GVBD-MII) }\end{array}$} & \multirow[b]{2}{*}{ (n) } \\
\hline & GV & GVBD & $\mathrm{Ml}$ & $\mathrm{Al}$ & $\mathrm{TI}$ & MII & Degen & & \\
\hline Low $\mathrm{O}_{2}$ & $35.0 \pm 13.4$ & $27.1 \pm 12.1$ & $4.0 \pm 4.0$ & $4.8 \pm 2.5$ & $3.8 \pm 2.4$ & $2.0 \pm 2.0$ & $23.2 \pm 6.6$ & $41.8 \pm 13.1^{*}$ & 66 \\
\hline High $\mathrm{O}_{2}$ & $52.3 \pm 9.9$ & $12.7 \pm 6.4$ & $3.0 \pm 3.0$ & $0.0 \pm 0.0$ & $0.0 \pm 0.0$ & $0.0 \pm 0.0$ & $31.9 \pm 2.2$ & $15.8 \pm 8.2$ & 52 \\
\hline
\end{tabular}

$* P$ value $<0.05$, high $\mathrm{O}_{2}$ compared with low $\mathrm{O}_{2}$. GV, germinal vesicle; GVBD, germinal vesicle breakdown; $\mathrm{MI}$, metaphase I; $\mathrm{Al}$, anaphase I; $\mathrm{TI}$, telophase I; MII, metaphase II.

\section{Nuclear maturation}

A total of 118 oocytes from three different repeats were cultured in low- or high- $\mathrm{O}_{2}$ conditions. After $52 \mathrm{~h}$ of culture (Table 1), there was no significant difference in degeneration rates of the oocytes cultured under two gas compositions $(P>0.05)$. However, a higher percentage of oocytes resumed meiosis after GV breakdown (GVBD) toward MII stage in low $\mathrm{O}_{2}(41.8 \pm 13.1 \%)$ compared with the oocytes cultured in high- $\mathrm{O}_{2}$ incubator (15.8 $\pm 8.1 \%)(P$ value $=0.014$; Table 1$)$.

\section{Extended IVM}

A total number of 460 oocytes (three repeats) were cultured in base maturation media for $52 \mathrm{~h}(n=66), 72 \mathrm{~h}$ $(n=231)$, and $84 \mathrm{~h}(n=163)$. The number of oocytes that remained at GV stage in the $52 \mathrm{~h}$ group was higher $(P<0.05)$ than the other two and the lowest MII stage percentage occurred within this group. Highest meiotic resumption (GVBD-MII) was in the 72-h cultured group $(64.1 \pm 6.0 \%)$, which was higher than $52 \mathrm{~h}(P<0.05$; Table 2). On the other hand, the 84-h group resulted in the highest rate of degeneration with $43.2 \pm 4.5 \%$ compared with $52 \mathrm{~h}(P<0.05 ;$ Table 2$)$. Although there were no significant differences in anaphase I (AI) or telophase I (TI) percentages among the three groups, the highest MII maturated oocytes $(7.5 \pm 4.0 \%)$ occurred at 84 h $(P<0.05$; Table 2).

\section{ROS and oxygen level}

To analyze the effects of oxygen level during IVM, oocytes $(n=130)$ were stained for $\mathrm{H}_{2} \mathrm{O}_{2}$ levels using $2^{\prime}, 7^{\prime}$-dichlorodihydrofluorescein diacetate (DCHFDA) after $72 \mathrm{~h}$ culture. Densitometry using ImageJ software showed that the overall intensity of fluorescence was greater for high $\mathrm{O}_{2}$ oocytes higher than low- $\mathrm{O}_{2}$ oocytes $(P=0.004$; Fig. 2).

\section{ROS repair enzymes mRNA expression}

Analyses of the fold induction of target genes (GPX1, SOD1, SOD2, GSR, and CAT) at 0 and $72 \mathrm{~h}$ in culture showed significant end point differences between COCs cultured in low- and high-oxygen incubators after $72 \mathrm{~h}(P<0.05)$. The expression of mitochondrial Mn-SOD2 among other enzymes involved in GSH metabolism was more prominent in the high-oxygen group (Fig. 3).

\section{Vitamin $E$ and oxidative stress}

COCs cultured in low- and high-oxygen incubators were supplemented with vitamin E during $72 \mathrm{~h}$ of IVM. Vitamin $\mathrm{E}$ at $100 \mu \mathrm{M}$ reduced degeneration in the highoxygen group compared with its control $(41.7 \pm 7.6 \%$ down to $30.4 \pm 2.3 \% ; P=0.008$; Table 3 ). Meiotic resumption in control $(P=0.0001)$ and vitamin $\mathrm{E}$ $(P=0.007)$-treated oocytes in the low-oxygen group was higher than their high-oxygen counterparts (Fig. 4). Also vitamin $E$ has no significant effect on the percentage of MIl-matured oocytes in both control groups $($ low $=13.1 \pm 3.1 \%$ and high $=4.6 \pm 2.5 \% ; \quad P=0.072$; Table 3). However, in the presence of vitamin $E$, the MII maturation rate in the low-oxygen group was higher than in high-oxygen group ( $P=0.008$; Fig. 4$)$.

Table 2 Effect of the duration of culture period from 52 to $84 \mathrm{~h}$ on nuclear maturation of canine oocytes $\left(5 \% \mathrm{O}_{2}, 5 \% \mathrm{CO}_{2}\right.$, and $\left.90 \% \mathrm{~N}_{2}\right)$. Table shows distribution of oocytes in different stages of meiotic division.

\begin{tabular}{|c|c|c|c|c|c|c|c|c|c|}
\hline & \multicolumn{7}{|c|}{ Percentage of oocytes (average \pm S.E.M.) in 52 vs 72 vs $84 \mathrm{~h}$ and low oxygen } & \multirow{2}{*}{$\begin{array}{c}\text { Meiotic } \\
\text { resumption } \\
\text { (GVBD-MII) }\end{array}$} & \multirow[b]{2}{*}{ (n) } \\
\hline & GV & GVBD & MI & $\mathrm{Al}$ & $\mathrm{TI}$ & MII & Degen & & \\
\hline $52 \mathrm{~h}$ & $35.0 \pm 13.4$ & $27.1 \pm 12.0$ & $4.0 \pm 4.0$ & $4.8 \pm 2.4$ & $3.8 \pm 2.4$ & $2.0 \pm 2.0$ & $23.2 \pm 6.6$ & $41.8 \pm 13.1$ & 66 \\
\hline $72 \mathrm{~h}$ & $4.0 \pm 1.1^{*}$ & $37.2 \pm 8.4^{*}$ & $16.5 \pm 2.5$ & $2.9 \pm 1.8$ & $3.7 \pm 0.8$ & $3.8 \pm 0.8$ & $31.9 \pm 5.4^{*}$ & $64.1 \pm 5.9^{*}$ & 231 \\
\hline $84 \mathrm{~h}$ & $0.7 \pm 0.7^{*}$ & $22.5 \pm 4.2$ & $20.6 \pm 4.8^{*}$ & $2.8 \pm 1.4$ & $2.5 \pm 1.3$ & $7.5 \pm 3.9^{*}$ & $43.2 \pm 4.4^{*}$ & $56.0 \pm 5.1$ & 163 \\
\hline
\end{tabular}

${ }^{*} P$ value $<0.05$, within the column compared with 52 h. GV, germinal vesicle; GVBD, germinal vesicle breakdown; MI, metaphase I; Al, anaphase I; TI, telophase I; MII, metaphase II. 

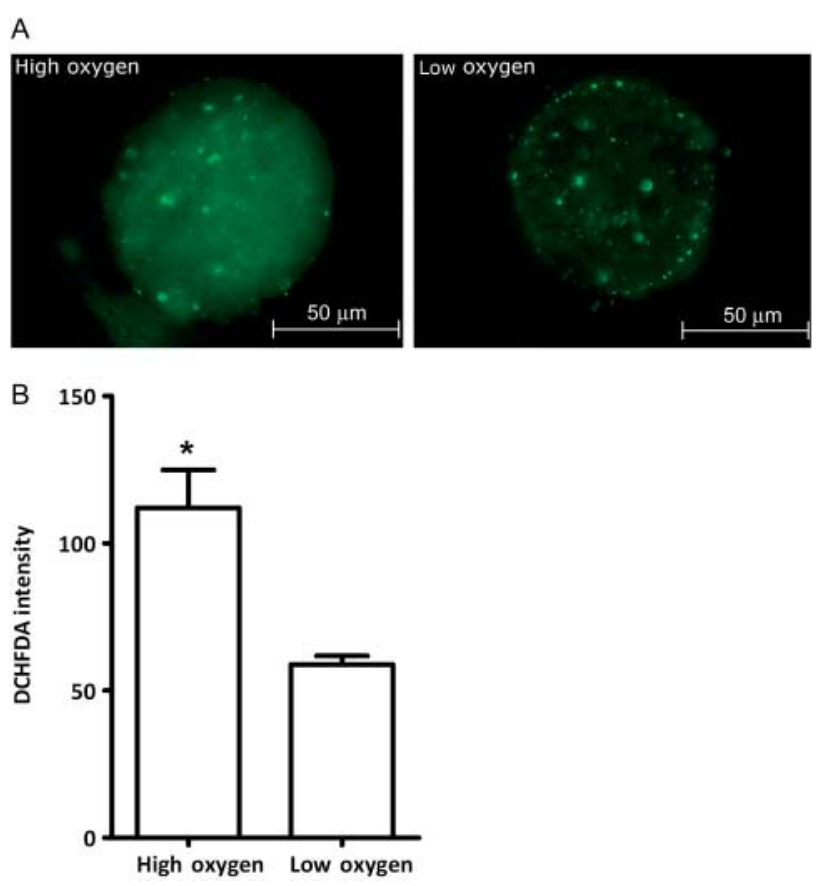

Figure 2 Effect of oxygen concentration on $\mathrm{H}_{2} \mathrm{O}_{2}$ (ROS) levels of canine oocytes after $72 \mathrm{~h}$ of culture. (A) Oocytes were stained with DCHFDA for $30 \mathrm{~min}$ at $38.5^{\circ} \mathrm{C}$ in the dark and then mounted on superfrost slides using Vectashield mounting media. Slides were visualized using fluorescence (470 nm wavelength LED lamp) and photographs taken immediately. (B) The total intensity of DCHFDA fluorescence signal of oocytes cultured in low $(5 \%)$ and high $(20 \%)$ oxygen levels in the base maturation media after $72 \mathrm{~h}$. DCHFDA intensity is a direct indicator of $\mathrm{H}_{2} \mathrm{O}_{2}$ level. $* P$ value $<0.05$.

\section{Discussion}

Establishment of an efficient IVM system for canine oocytes, which is complicated by unique and complex canine reproductive physiology, is still unsolved. During this study, attempts were made to establish a chemically defined and time course optimally modified IVM protocol for canine oocytes. The majority of IVM protocols are based on serum-enriched culture media (Otoi et al. 1999, Luvoni et al. 2005, Oh et al. 2005) in which the exact beneficial effects of serum are unknown and in most cases unpredictable (Bolamba et al. 2002, Lee et al. 2007 b). In addition, results from our preliminary experiments (unpublished data) indicated that presence of fetal bovine serum tends to have detrimental effects on nuclear maturation of canine oocytes and significantly increases degeneration rates. Thus, in this study, all the experiments were carried out in a chemically defined medium and without serum supplementation.

\section{Staining and staging}

Nuclear staining and staging of canine oocytes after IVM is one of the most critical issues in canine-assisted reproductive techniques. Therefore, it is worth mentioning that we have optimized a protocol that allows precise assessment of oocyte nuclear stage during meiotic maturation. It includes a procedure for complete denuding of cumulus cells and fixation followed by staining of oocytes and visualization of oocyte chromatin under a fluorescence microscope. Denuding canine oocytes due to their highly inter-digitated cumulus, ZP attachment (Blackmore et al. 2004, De los Reyes et al. 2009) after culture, is challenging (Hewitt et al. 1998). In addition, the lipid droplets inside the oocyte make it very difficult to visualize the chromatin content by simple aceto-orcein staining unless oocytes are fixed for 5-7 days (Song et al. 2010). After trying several denuding buffers with different timetables of incubation and vortexing (Reynaud et al. 2004), incubation in sodium tri-citrate 1\% (Hewitt \& England 1999) and denuding using an oocyte holding needle with gauge of $135 \mathrm{~m}$ (Yellow EZ-Strip Research Instruments Limited, Cornwall, UK) resulted in complete removal of the cumulus cells. For nuclear staining, the combination of 10-min fixation with acetone at $-20^{\circ} \mathrm{C}$ followed by $5 \mathrm{~min}$ staining in $10 \mu \mathrm{g} / \mathrm{ml}$ Bisbenzimide (Hoechst 33342) solution provided a quick and reliable solution. Using this method, we were able to provide a panel of images that can be used as guidance for investigators (Fig. 5).

\section{Oxygen level and IVM}

Expansion of cumulus cells did not differ after $52 \mathrm{~h}$ of culture of COCs in low- $(5 \%)$ or high $(20 \%)$-oxygen

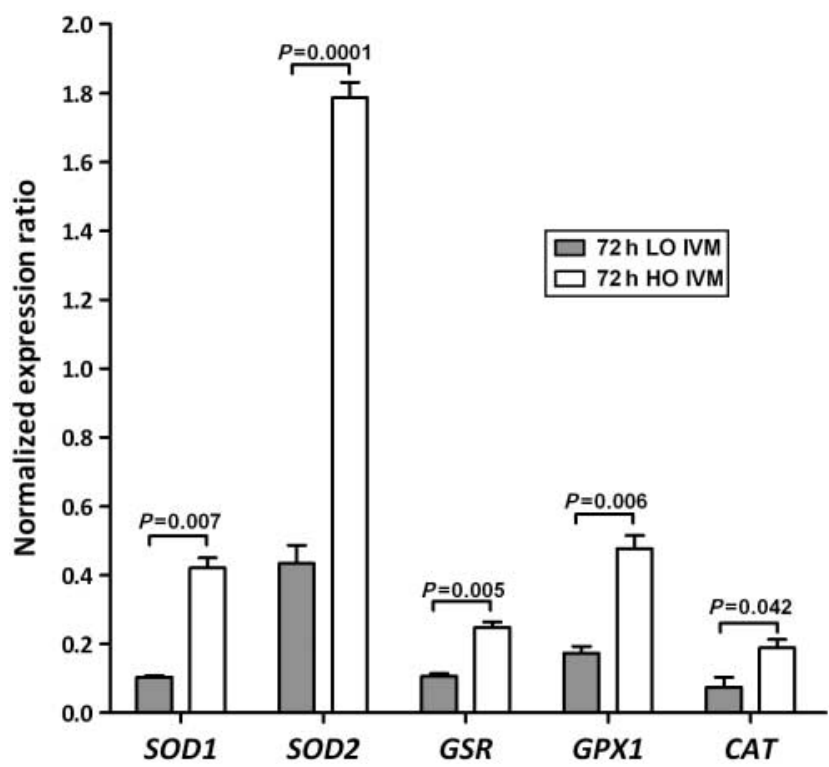

Figure 3 Effect of oxygen concentration on mRNA expression profile of ROS repairing enzymes in canine oocytes. Graph shows the fold induction of ROS repairing enzymes after $72 \mathrm{~h}$ of IVM compared with $0 \mathrm{~h}$ and normalized to the GAPDH housekeeping gene. SOD1, cytosolic superoxide dismutase; SOD2, mitochondrial superoxide dismutase; GSR, glutathione reductase; GPX1, glutathione peroxidase; CAT, catalase; LO, low oxygen; HO, high oxygen. 
Table 3 Effect of vitamin E on the nuclear maturation of canine oocytes in low and high oxygen. Table shows distribution of oocytes in different stages of meiotic division.

\begin{tabular}{lcccccccc}
\hline & \multicolumn{4}{c}{ Percentage of oocytes (average \pm S.E.M.) in vitamin E experiment $(72$ h) } & \multicolumn{2}{c}{$\begin{array}{c}\text { Meiotic } \\
\text { resumption }\end{array}$} \\
\cline { 2 - 7 } & GV & GVBD & MI & Al & TI & MII & Degen & $($ GVBD-MII) \\
$(n)$
\end{tabular}

${ }^{*} P$ value $<0.05$ within the column in low or high oxygen compared with their controls; ${ }^{+{ }^{+}} P$ value $<0.05$ within the column between control groups $\left({ }^{+}\right)$, between vitamin E groups $\left(^{\ddagger}\right)$. GV, germinal vesicle; GVBD, germinal vesicle breakdown; $\mathrm{MI}$, metaphase I; $\mathrm{Al}$, anaphase I; $\mathrm{TI}$, telophase I; MII, metaphase II.

incubators; nevertheless, the disintegration of cumulus cells differed in high oxygen (Fig. 1). The oviductal oxygen level is almost one-forth to one-third of the normal air oxygen level (e.g. 5 vs $20 \%$ ) (Rodrigues \& Rodrigues 2010). Despite the presence of anti-apoptotic intracellular mechanisms acting via GSH against ROS (Silva et al. 2009), having high lipid content in canine COCs can reduce GSH level and predispose them to oxidative damage and induce apoptosis in the cumulus cells (Silva et al. 2009). This can contribute to lowered oocyte maturation rates (Kim et al. 2007, Rodrigues \& Rodrigues 2010). Expansion of cumulus cells in vivo or during culture of COCs in vitro occurs through production of hyaluronan by cumulus cells under the influence of $\mathrm{LH}$. Cumulus cells must be viable and express hyaluronan synthase II in the cell membrane (Marei et al. 2012). Induction of apoptosis in COCs through oxidative stress during the extended culture period is expected to hamper production of hyaluronan and cumulus cells expansion. Albeit that cumulus cell expansion is not a convincing marker of canine oocyte maturation (Reynaud et al. 2005, Otoi et al. 2007, Rodrigues \& Rodrigues 2010), there was significantly higher number of maturing oocytes (GVBD-MII) after $52 \mathrm{~h}$ culture in the low-oxygen $(41.8 \pm 13.1 \%)$ group compared with the high-oxygen group $(15.8 \pm 8.2 \%)$. This was accompanied by lower degeneration rate in the low-oxygen group $(23.2 \pm 6.6 \%)$ compared with the high-oxygen group $(31.9 \pm 2.2 \%)(P<0.05)$, confirming the detrimental effects of high oxygen tension on dog oocytes.

Duration of culture period for IVM of canine oocytes ranges from 48 to $96 \mathrm{~h}$ in different studies (Luvoni et al. 2005, Rodrigues \& Rodrigues 2010). In vivo, oocytes need 2-4 days for completion of this stage (Concannon 2011). Therefore, it was decided to extend the culture period up to $84 \mathrm{~h}$ in order to find the optimal culture period for canine oocytes, which result in highest maturation and lowest degeneration rates in the lowoxygen atmosphere. Extension of culture period to $72 \mathrm{~h}$ resulted in increased meiotic resumption to $64.1 \pm 5.9 \%$ (Table 2). However, further extension of the culture period to $84 \mathrm{~h}$ resulted in elevation $(7.4 \%)$ in the percentage of MII oocytes (Table 2) but increased degeneration rate. Similar findings were reported by other research groups (Otoi et al. 2002, Rodrigues Bde et al. 2004). Therefore, for the remainder of experiments presented here including $\mathrm{H}_{2} \mathrm{O}_{2}$ comparison, ROS, and vitamin E experiments, 72-h incubation period was used to avoid high degeneration but achieve highest meiotic resumption.

\section{Oxidative stress and IVM}

In the $\mathrm{H}_{2} \mathrm{O}_{2}$ staining (DCHFDA) experiment, a comparison was done between low and high oxygen levels and the total amount of $\mathrm{H}_{2} \mathrm{O}_{2}$ produced inside ooplasm of canine oocytes after $72 \mathrm{~h}$ of culture. Oocytes stained with DCHFDA (Fig. 2A) produced significantly higher levels of $\mathrm{H}_{2} \mathrm{O}_{2}(P=0.004)$ in the high-oxygen group (Fig. 2B). It is noteworthy that $\mathrm{H}_{2} \mathrm{O}_{2}$ is a byproduct of the ROS protection system in which SOD enzymes transform damaging oxygen-free radicals into less aggressive $\mathrm{H}_{2} \mathrm{O}_{2}$ molecules (Whitaker \& Knight 2008). As oxidative stress is introduced to oocytes immediately after mechanical extraction till the end of the culture period via various sources of free radicals, light and physical trauma (Guerin et al. 2001, Menezo et al. 2010), it is necessary to provide these cells with least amount of

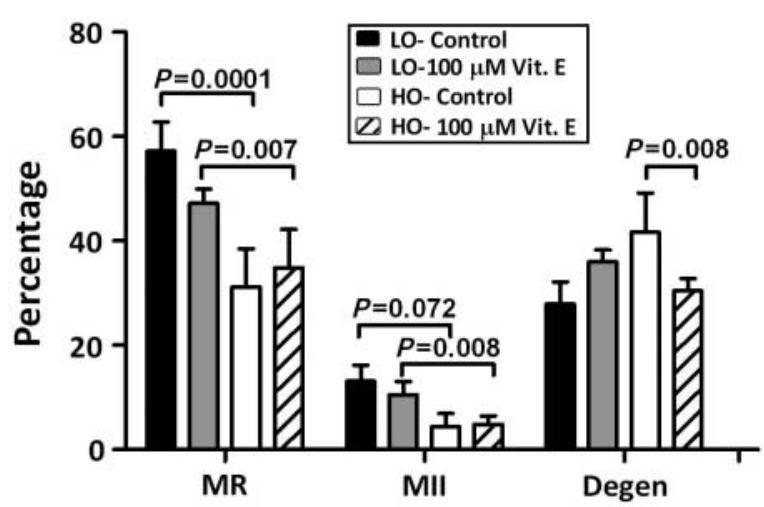

Figure 4 Effect of vitamin $\mathrm{E}$ on the nuclear maturation of canine oocytes in low and high oxygen. Graph shows the percentages of meiotic resumption (MR; GVBD-MII), metaphase II (MII), and degenerated (Degen) oocytes cultured in the presence or absence of vitamin $\mathrm{E}$. LO, low oxygen; HO, high oxygen. 

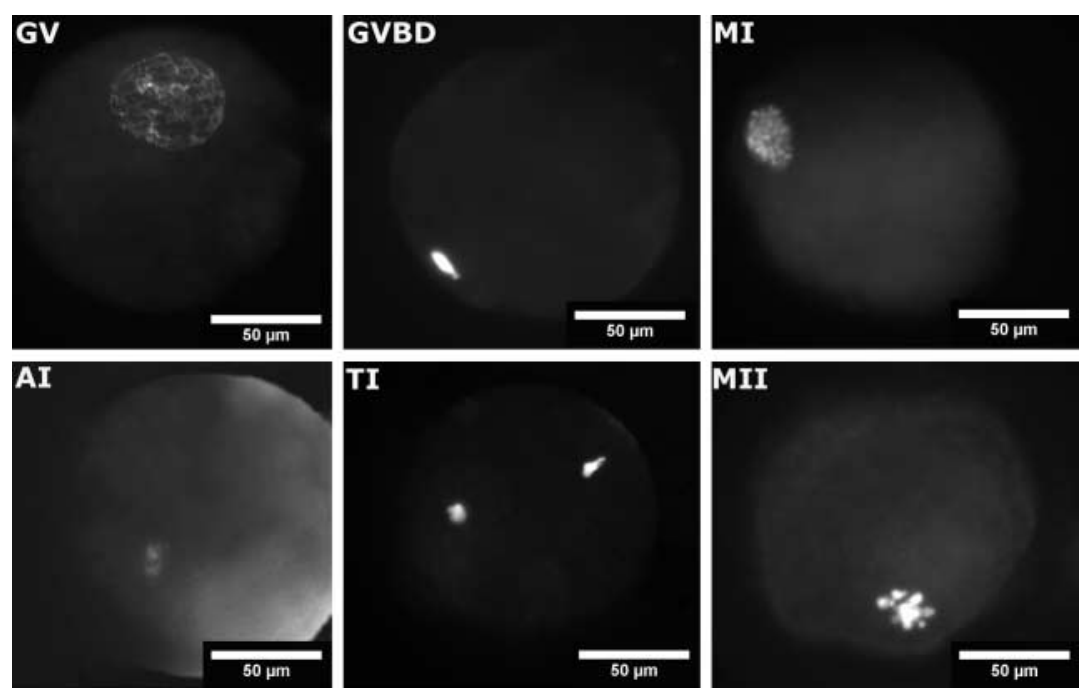

Figure 5 Canine oocytes at different stages of meiotic division: oocytes were stained with Hoechst $33342(10 \mu \mathrm{g} / \mathrm{ml})$ and visualized by fluorescence microscope with $40 \times$ objective. Prophase 1 (germinal vesicle, GV), germinal vesicle breakdown, GVBD accompanied by chromatin condensation, metaphase I (MI), anaphase I (AI), telophase I (TI), metaphase II (MII).

stressors. Reduction of oxidative stress can profoundly contribute to improved nuclear and cytoplasmic maturation.

Results of the real-time qPCR showed that mRNA of ROS repair enzymes are significantly higher in oocytes cultured in high oxygen (Fig. 3), which is concomitant with high $\mathrm{H}_{2} \mathrm{O}_{2}$ level, lower meiotic resumption, and higher degeneration rates. SOD, present in mitochondria (SOD2), showed remarkable increase in mRNA expression in the high-oxygen group, which is in agreement with previous reports (De los Reyes et al. 2011). Involvement of mitochondrial mobilization during cytoplasmic maturation of canine oocytes in terms of perturbation due to oxidative pressure could be the main retarding factor in canine IVM. Moreover, oocytes cultured in high oxygen showed increased GPX1 and GSR expression in response to high oxygen tension (Fig. 3), indicating that the mitochondrial oxidative profile requires further investigation.

Supplementation of vitamin $E$ in the maturation medium did not prevent the detrimental effects of high oxygen tension on degeneration rates of canine oocytes during 72-h culture. Meiotic resumption of oocytes cultured in low oxygen tension was higher in both control and $100 \mu \mathrm{M}$ vitamin E-treated oocytes than in the high-oxygen group. Vitamin $E$ in the presence of high oxygen was able to decrease degeneration $(P=0.008)$ but did not improve the percentage of oocytes in MII. The beneficial effect of vitamin $\mathrm{E}$ on oocyte maturation and embryo development was previously reported in animal species regardless of lipid content, including porcine cells (Tao et al. 2010), which contain high lipid, or in ovine oocytes (Natarajan et al. 2010), which contain relatively low lipid contents.

The studies presented here concerned culture of canine oocytes in a serum-free and chemically defined maturation media. Culture period of $72 \mathrm{~h}$ in low oxygen level $(5 \%)$ was the optimal condition for canine COCs.
Oxidative stress and the level of ROS in canine ooplasm affected maturation efficiency, particularly involving mitochondrial activity. To the best of authors' knowledge, this is the first study that demonstrated the importance of oxygen tension during canine IVM and its possible contributions to maturation and degeneration.

\section{Materials and Methods}

\section{Chemicals and reagents}

All the materials and chemical reagents were purchased from Sigma-Aldrich Chemical Co. unless otherwise stated.

\section{Collection of ovaries}

The sample collection procedure was carried out after routine ovariectomy of bitches by approval of the ethics committee of the Royal Veterinary College from a small animal hospital under supervision and consent of dog owners. Ethical approval was also verified by the University of Bedfordshire Ethical Scrutiny Committee. Due to the nature of this study and also previously published reports (Otoi et al. 2000, 2001, 2002, Songsasen \& Wildt 2005), sample collection was blind to reproductive stage of the animal, breed, age, weight, or size.

\section{Collection of COCs}

Ovaries were collected immediately after ovariectomy and placed in a $60 \mathrm{ml}$ container (VWR International, Westchester, PA, USA) half full of warm $\left(37^{\circ} \mathrm{C}\right)$ sterile PBS and transferred to the laboratory $<2 \mathrm{~h}$ after surgery. The container was immersed in a thermos flask containing warm PBS. Before dissection of follicle and oocytes, the ovaries were washed with warm PBS and trimmed of the ovarian bursa and other debris with a scalpel blade. The ovaries were washed with a sterile filtered $(0.2 \mu \mathrm{m}$ microbial filter (Anachem, Bedfordshire, UK)) washing media (TCM199+20 mM HEPES buffer $+10 \%$ FBS (PAA 
Laboratories, Dartmouth, MA, USA)) and then sliced gently using a set of multiple blades (Fisher Scientific, Loughborough, UK) as described previously (Alhaider \& Watson 2009). COCs with an oocyte diameter over $100 \mu \mathrm{m}$ (surrounded by at least three layers of cumulus cells) having dense and homogenous lipid yolk in the ooplasm were selected and washed twice before culture.

COCs selection criteria for canine IVM protocols used to be quite controversial (Songsasen \& Wildt 2005, Concannon et al. 2009). Recently, it has been accepted that age (older than 6 months), breed, weight, and the stage of estrous cycle are less likely to affect the maturation rate of oocytes to MII stage or their degeneration rate (Concannon et al. 2009). Instead cellular criteria have been introduced for oocyte quality including condensed and homogenous lipid yolk, oocyte diameter above $100 \mu \mathrm{m}$ excluding the $\mathrm{ZP}$, and being surrounded with at least three layers of cumulus cells (Otoi et al. 2000, 2001, 2002). Oocyte diameter above $100 \mu \mathrm{m}$ is one of cellular criteria during selection that is highly recommended by many reports (Songsasen \& Wildt 2005). Nevertheless, large size of the oocyte is not necessarily a guarantee of either meiotic competency or cumulus expansion (Rodrigues \& Rodrigues 2010). During all experiments of this study, oocytes were collected from ovaries according to the above cellular criteria to maintain the unity.

\section{In vitro maturation}

Oocytes were cultured in 25 oocyte maximum groups according to Hewitt \& England (1999) with minor modifications. Selected oocytes were cultured in four-well culture dishes (NUNC, VWR International, Milan, Italy). The base maturation media was modified synthetic oviductal fluid (mSOF; Holm et al. 1999, Marei et al. 2009) supplemented with LH $5 \mu \mathrm{g} / \mathrm{ml}$ (Leutropin; Bioniche Animal Health, Belleville, ON, Canada), FSH $5 \mu \mathrm{g} / \mathrm{ml}$ (Follitropin; Bioniche Animal Health), $17 \beta$-estradiol $1 \mu \mathrm{g} / \mathrm{ml}$, progesterone $1 \mu \mathrm{g} / \mathrm{ml}$, $50 \mu \mathrm{g} / \mathrm{ml}$ gentamicin sulfate, and $6 \mathrm{mg} / \mathrm{ml} \mathrm{BSA}$.

\section{Assessment of cumulus cell expansion}

Cumulus expansion (mucification) was described by the partial or complete loosening of cumulus cells into extracellular matrix surrounding the oocyte (Lee et al. 2007a, Marei et al. 2009, Silva et al. 2009). COCs were assessed for expansion of cumulus cells at $24 \mathrm{~h}$ after the beginning of the culture and by the end of $52 \mathrm{~h}$ under a stereomicroscope.

\section{Denuding oocytes and assessment of nuclear maturation}

Oocytes were denuded by incubation in 1\% (W/V) Tri-Sodium Citrate in PBS buffer for 3-5 min and vortexed for $2 \mathrm{~min}$ at maximum agitation inside a $15 \mathrm{ml}$ conical centrifuge tube (VWR International). Remaining cumulus cells were denuded using an oocyte holding needle with gauge of $135 \mathrm{~m}$ (Yellow EZ-Strip Research Instruments Limited). The oocytes were placed in a drop on superfrost slides (VWR International) and air dried in room temperature for $20 \mathrm{~min}$. Afterward, the oocytes were fixed in cold $\left(-20^{\circ} \mathrm{C}\right) 99 \%$ Acetone (Merck) for
10 min. Hoechst 33342 fluorescent DNA dye (excitation/ emission $=350 / 461 \mathrm{~nm}$ ) was prepared in PBS at $10 \mu \mathrm{g} / \mathrm{ml}$ for simultaneous staining and rehydration of slides for $5 \mathrm{~min}$ at $4{ }^{\circ} \mathrm{C}$. Hoechst 33342 and PBS were dried with a stripped filter paper as much as possible before mounting the oocytes. Oocytes were mounted using Vectashield mounting medium (Vector Laboratories, Burlingame, CA, USA) beneath a coverslip fixed with four paraffin/vaseline drops $(1 / 40 ; w / w)$ at the corners of the coverslip. Nuclear stage of the oocytes was assessed with an Olympus BX60 fluorescence microscope (Olympus, UK).

During maturation, oocytes go through different stages between prophase I and MII. By the time they had reached the end of culture period, they were distributed among seven groups according to nuclear stage. The number of oocytes at each stage was recorded (Hewitt et al. 1998). Degenerate oocytes with undetermined, disappeared, or morphologically abnormal nuclear material were categorized as a separate group (Degen) in all experiments. A panel of stained oocytes at different meiotic stages is shown in Fig. 5, which was used as a guide for all experiments.

\section{ROS staining using DCHFDA}

A total number of 130 oocytes from high- and low- $\mathrm{O}_{2}$ groups in three replicates were denuded after $72 \mathrm{~h}$ of culture and stained using DCHFDA. This substance hydrolyzes via intracellular esterase to produce $2^{\prime}, 7^{\prime}$-dichlorodihydrofluorescein (DCHF), and the latter metabolite will be oxidized via $\mathrm{H}_{2} \mathrm{O}_{2}$ to $2^{\prime}, 7^{\prime}$ dichlorofluorescein (DCF; Nasr-Esfahani et al. 1990, Wakefield et al. 2008). With DCF excitation at $470 \mathrm{~nm}$ wavelength, the emission at 522-530 nm could be captured by fluorescence microscopy. Thus, the oocytes were washed twice in $0.04 \%$ PVP in PBS and then incubated for $30 \mathrm{~min}$ at $38.5^{\circ} \mathrm{C}$ in the dark in the $0.04 \%$ PVP-PBS buffer containing $10 \mu \mathrm{M}$ DCHFDA. Afterward, oocytes were washed two times in the same buffer and mounted on slides using Vectashield mounting media (VectorLabs, Peterborough, UK) under a coverslip. Oocytes were visualized by $470 \mathrm{~nm}$ LED lamp Olympus BX60 fluorescence microscope, and photographs were obtained from ten oocytes of the two groups in each repeat. The intensity of fluorescent signal was quantified using Imagej software particle analysis plug-in (Abràmoff et al. 2004).

\section{Real-time PCR and expression profile of ROS repair enzymes}

Mechanically dissected COCs $(n=340)$ cultured in high and low oxygen were snap frozen after $72 \mathrm{~h}$ of culture in PBS-PVP $0.4 \%$ (polyvinylpyrrolidone) using liquid nitrogen and kept at $-20{ }^{\circ} \mathrm{C}$ until analysis. RNA extraction was done using a QIAGEN RNAeasy kit (Qiagen). Briefly, 20 COCs were lysed in $350 \mu \mathrm{l}$ lysis buffer (RLT), mixed with equal amount of $70 \%$ ethanol, and transferred to the RNAeasy spin columns. Washes and centrifugation were carried out according to the manufacturer's instruction, and RNAs were finally eluted in $30 \mu \mathrm{l}$ nuclease-free water and the concentration was measured by a TECAN plate reader (TECAN, Switzerland). RNA concentration was normalized among samples by dilution to $50 \mathrm{ng}$ in $8 \mu \mathrm{l}$ 
Table 4 Sequence of the designed primers and accession numbers of the ROS repairing enzyme genes.

\begin{tabular}{|c|c|c|c|}
\hline Canine genes & Accession number & Oligos $\left(5^{\prime} \rightarrow 3^{\prime}\right)$ & Product size (bp) \\
\hline$G P X 1$ & NM_001115119.1 & $\begin{array}{l}\text { F: GACACCACTGCGCTAATGAC } \\
\text { R: AGGGAAAGGAGGGTTGCCTA }\end{array}$ & 215 \\
\hline SOD1 & NM_001003035.1 & $\begin{array}{l}\text { F: ACCATTACAGGGCTGACTGAAG } \\
\text { R: TGGACAGAGGATTAAAGTGAGGA }\end{array}$ & 115 \\
\hline SOD2 & XM_533463.3 & $\begin{array}{l}\text { F: AGAAGGGTGACATTACAGCTCA } \\
\text { R: AATCACGTTTGATGGCTTCC }\end{array}$ & 153 \\
\hline$C A T$ & NM_001002984.1 & $\begin{array}{l}\text { F: CCCATTGCAGTTCGATTCTC } \\
\text { R: CTATGGATAAAGGACGGAAACA }\end{array}$ & 179 \\
\hline$G S R$ & XM_532813.3 & $\begin{array}{l}\text { F: CTACGTGAGCCGCCTAAATAC } \\
\text { R: CTGTGGCAATCAGGATGTGAG }\end{array}$ & 155 \\
\hline GAPDH & NM_001003142.1 & $\begin{array}{l}\text { F: GTGATGCTGGTGCTGAGTATGT } \\
\text { R: ATGGATGACTTTGGCTAGAGGA }\end{array}$ & 233 \\
\hline
\end{tabular}

volume. DNA digestion was carried out using RQ1 RNAasefree DNAse kit (Promega; M6101). RT of RNA samples was conducted by Promega RT kit (Promega) in a equal amount of $50 \mathrm{ng}$ RNA (total $20 \mu \mathrm{l}$ ) and the PCRs were done in $12.5 \mathrm{ng}$ CDNA per reaction in duplicate tubes and four sets of repeats. Conventional PCR (38 cycles) was conducted on every batch of cDNA including the negative control for RT for every primer before temperature gradient optimization. A temperature gradient real-time PCR was done in the range of $50-60{ }^{\circ} \mathrm{C}$ and except $C A T\left(57^{\circ} \mathrm{C}\right)$, the rest of primers had an optimal melting temperature at $59^{\circ} \mathrm{C}$. Quantitative PCR was done using KAPA SYBR FAST qPCR Kits (Kapa Biosystems, Bedfordshire, UK) and $20 \mu \mathrm{M}$ primers in $20 \mu \mathrm{l}$ volume and 38 cycles via Bio-Rad CFX96 real-time machine (Bio-Rad) using CFX manager 1.7 software (Bio-Rad). Genomic sequences were obtained from PubMed, and primers were designed using Primer3 (Rozen \& Skaletsky 2000) web-based software (Table 4).

Relative real-time qPCR was carried out using canine $G A P D H$ as the housekeeping gene, which had a stable expression among three groups (control $(0 \mathrm{~h})$ and the two treatments) in four replicates (Levene's test, $P=0.086$; one-way ANOVA (equal variances assumed, LSD post-HOC); $P$ value $=0.227$ ). The fold induction (expression) of target genes was analyzed using Livak method $\left(2^{-\Delta \Delta C T}\right.$ ) (Livak \& Schmittgen 2001).

\section{Experimental design}

Experiments were repeated at least three times. A total of 1249 oocytes presenting homogenous and condensed lipid contents in the cytoplasm surrounded by at least three layers of cumulus cells were used. During the first experiment, 118 COCs were cultured in humidified incubators under two different gas compositions for $52 \mathrm{~h}$ at $38.5{ }^{\circ} \mathrm{C}$ : high $\mathrm{O}_{2}\left(\left(5 \% \mathrm{CO}_{2}\right.\right.$ in air $\left.\left(\sim 20 \% \mathrm{O}_{2}\right)\right)$ or low $\mathrm{O}_{2}\left(5 \% \mathrm{CO}_{2}, 5 \% \mathrm{O}_{2}\right.$, and $\left.90 \% \mathrm{~N}_{2}\right)$ in order to study the pattern of cumulus expansion. COCs were photographed twice during the $52 \mathrm{~h}$ of culture (at 24 and $52 \mathrm{~h}$ ) using a digital camera and an inverted microscope to record any pattern of cumulus expansion within different oxygen levels. At the end of culture $(52 \mathrm{~h})$, COCs were denuded fixed and stained to assess nuclear maturation of the oocytes. Each stage of meiotic resumption was reported as a percentage of total number of the oocytes cultured from one animal/replicate.
From results of the nuclear maturation rates, a second experiment was designed to compare nuclear maturation rates of canine oocytes in longer incubation periods. A total number of 460 COCs were cultured in the low oxygen for 72 and $84 \mathrm{~h}$ time periods; oocyte maturation and degeneration rates were analyzed after staining.

The third experiment was designed to assess the role of oxidative stress as a detrimental factor, which may contribute to the high degeneration and low maturation rates in canine IVM oocytes. A total number of 130 oocytes were cultured for $72 \mathrm{~h}$ in the low or high oxygen gas atmospheres. The $\mathrm{H}_{2} \mathrm{O}_{2}$ concentration in oocytes as the product of ROS was quantified after DCHFDA fluorescent staining. Photographs of stained oocytes were analyzed via Imagej software to quantify the spot density of fluorescence, which is directly correlated with the amount of $\mathrm{H}_{2} \mathrm{O}_{2}$ produced inside each oocyte (Nasr-Esfahani et al. 1990, Wakefield et al. 2008). An average of total intensity was compared between the low- and high-oxygen groups.

For investigating the mRNA expression profile of ROSdefensive enzymes, 340 oocytes in four repeats were cultured in low- and high-oxygen incubators (groups of 20). At the beginning of the experiment, 20 COCs were snap frozen as the 0-h control group. At the end of the 72-h culture period, oocytes were snap frozen as low- and high-oxygen treatment groups. PCR reactions were carried out in duplicates and four repeats. In Livak analysis, cycles of threshold (Ct) of the target genes (TG) were first deduced by the $\mathrm{Ct}$ of housekeeping gene $(\mathrm{HKG} ; \mathrm{GAPDH}): \Delta \mathrm{Ct}=$ average $\mathrm{C}(\mathrm{t})(\mathrm{TG})$-average $\mathrm{C}(\mathrm{t})(\mathrm{HKG})$. Resulting values for treatment groups $(72 \mathrm{~h})$ were normalized against the $0-\mathrm{h}$ control using the following equation: $\Delta \Delta \mathrm{Ct}$ $(\mathrm{TG})=\Delta \mathrm{Ct}$ treatment $72 \mathrm{~h}(\mathrm{TG})-\Delta \mathrm{Ct} \mathrm{Ctrl} 0 \mathrm{~h}(\mathrm{TG})$; normalized expression ratio $=2^{-\Delta \Delta \mathrm{Ct}(\mathrm{TG})}$.

Experiment 4 concerned protective effects of vitamin $E$ over oxidative stress. A total of 201 oocytes were cultured in low- and high-oxygen incubators in two groups in absence (control) and presence of $100 \mu \mathrm{M}$ vitamin E. Nuclear maturation rates and meiotic resumption of oocytes were analyzed after $72 \mathrm{~h}$ of culture using fluorescent staining.

\section{Statistical analysis}

All experiments in this study were repeated at least three times. The proportional average of oocytes in different stages of meiotic resumption was calculated at the end of the culture 
period in comparison to the total number. The oocytes were categorized in to seven groups of GV, GVBD, metaphase I, AI, $\mathrm{TI}, \mathrm{MII}$, and degenerates (Degen). Statistical analysis was carried out in PAWS statistics 18: Statistical Package for Social Sciences (SPSS, Inc., Chicago, IL, USA) using binary and ordinal logistic regressions via generalized linear model. Analysis of qPCR data was carried out using CFX manager software (Bio-Rad) and one-way ANOVA (LSD PostHoc multiple comparisons) in PAWS statistics 18: Statistical Package for Social Sciences (SPSS, Inc.).

\section{Declaration of interest}

The authors declare that there is no conflict of interest that could be perceived as prejudicing the impartiality of the research reported.

\section{Funding}

This work was supported by a match funding PhD scholarship from the University of Bedfordshire to M Salavati.

\section{Acknowledgements}

The authors appreciate the selfless help and cooperation of Beaumont Sainsbury Animal Hospital of the Royal Veterinary College including Ms Louise Allum, head Veterinary Surgeon, and Ms Anne Richings, the hospital manager for providing the samples for this study. The authors would also like to thank pivotal help of Dr Waleed Marei for laboratory techniques and Dr Yu-Mei Chang for statistical analysis.

\section{References}

Abràmoff MD, Magalhães PJ \& Ram SJ 2004 Image processing with Imagej. Biophotonics International 11 36-42.

Alhaider AK \& Watson PF 2009 The effects of hCG and growth factors on in vitro nuclear maturation of dog oocytes obtained during anoestrus. Reproduction, Fertility, and Development 21 538-548. (doi:10.1071/ RD08167)

Blackmore DG, Baillie LR, Holt JE, Dierkx L, Aitken RJ \& McLaughlin EA 2004 Biosynthesis of the canine zona pellucida requires the integrated participation of both oocytes and granulosa cells. Biology of Reproduction 71 661-668. (doi:10.1095/biolreprod.104.028779)

Bolamba D, Russ KD, Olson MA, Sandler JL \& Durrant BS 2002 In vitro maturation of bitch oocytes from advanced preantral follicles in synthetic oviduct fluid medium: serum is not essential. Theriogenology $\mathbf{5 8}$ 1689-1703. (doi:10.1016/S0093-691X(02)01080-4)

Chastant-Maillard S, Chebrout $M$, Thoumire S, Saint-Dizier $M$, Chodkiewicz M \& Reynaud K 2010 Embryo biotechnology in the dog: a review. Reproduction, Fertility, and Development 22 1049-1056. (doi:10.1071/RD09270)

Chebrout M, de Lesegno CV, Reynaud K, Chat S \& Chastant-Maillard S 2009 Nuclear and cytoplasmic maturation of canine oocytes related to in vitro denudation. Reproduction in Domestic Animals 44 (Suppl 2) 243-246. (doi:10.1111/j.1439-0531.2009.01371.x)

Chen L, Wert SE, Hendrix EM, Russell PT, Cannon M \& Larsen WJ 1990 Hyaluronic acid synthesis and gap junction endocytosis are necessary for normal expansion of the cumulus mass. Molecular Reproduction and Development 26 236-247. (doi:10.1002/mrd.1080260307)

Concannon PW 2011 Reproductive cycles of the domestic bitch. Animal Reproduction Science 124 200-210. (doi:10.1016/j.anireprosci.2010. 08.028)
Concannon PW, Castracane VD, Temple M \& Montanez A 2009 Endocrine control of ovarian function in dogs and other carnivores. Animal Reproduction 6 172-193.

Dalvit G, Llanes SP, Descalzo A, Insani M, Beconi M \& Cetica P 2005 Effect of $\alpha$-tocopherol and ascorbic acid on bovine oocyte in vitro maturation. Reproduction in Domestic Animals 40 93-97. (doi:10.1111/j.14390531.2004.00522.x)

De los Reyes M, Hetz J \& Palomino J 2009 Ultrastructural study of the canine zona pellucida surface during in vitro maturation. Reproduction in Domestic Animals 44 (Suppl 2) 247-250. (doi:10.1111/j.1439-0531. 2009.01374.x)

De los Reyes M, Palomino J, Parraguez VH, Hidalgo M \& Saffie P 2011 Mitochondrial distribution and meiotic progression in canine oocytes during in vivo and in vitro maturation. Theriogenology 75 346-353. (doi:10.1016/j.theriogenology.2010.09.005)

Guerin P, El Mouatassim S \& Menezo Y 2001 Oxidative stress and protection against reactive oxygen species in the pre-implantation embryo and its surroundings. Human Reproduction Update 7 175-189. (doi:10.1093/humupd/7.2.175)

Guraya SS 1965 A histochemical analysis of lipid yolk deposition in the oocytes of cat and dog. Journal of Experimental Zoology 160 123-135. (doi:10.1002/jez.1401600111)

Hewitt DA \& England GC 1999 Synthetic oviductal fluid and oviductal cell coculture for canine oocyte maturation in vitro. Animal Reproduction Science 55 63-75. (doi:10.1016/S0378-4320(98)00162-6)

Hewitt DA, Watson PF \& England GC 1998 Nuclear staining and culture requirements for in vitro maturation of domestic bitch oocytes. Theriogenology 49 1083-1101. (doi:10.1016/S0093-691X (98)00058-2)

Holm P, Booth PJ, Schmidt MH, Greve T \& Callesen H 1999 High bovine blastocyst development in a static in vitro production system using SOFaa medium supplemented with sodium citrate and myo-inositol with or without serum-proteins. Theriogenology 52 683-700. (doi:10.1016/ S0093-691X(99)00162-4)

Kim MK, Hossein MS, Oh HJ, Fibrianto HY, Jang G, Kim HJ, Hong SG, Park JE, Kang SK \& Lee BC 2007 Glutathione content of in vivo and in vitro matured canine oocytes collected from different reproductive stages. Journal of Veterinary Medical Science 69 627-632. (doi:10.1292/ jvms.69.627)

Lee HS, Seo YI, Yin XJ, Cho SG, Lee SS, Kim NH, Cho SK \& Kong IK 2007 a Effect of follicle stimulation hormone and luteinizing hormone on cumulus cell expansion and in vitro nuclear maturation of canine oocytes. Reproduction in Domestic Animals 42 561-565. (doi:10.1111/ j.1439-0531.2006.00818.x)

Lee SR, Kim BS, Kim JW, Kim MO, Kim SH, Yoo DH, Shin MJ, Park YS, Lee S, Park YB et al. 2007b In vitro maturation, in vitro fertilization and embryonic development of canine oocytes. Zygote 15 347-353. (doi:10.1017/S0967199407004352)

Livak KJ \& Schmittgen TD 2001 Analysis of relative gene expression data using real-time quantitative PCR and the $2(-$ Delta Delta $C(\mathrm{~T}))$ method. Methods 25 402-408. (doi:10.1006/meth.2001.1262)

Lopes G, Rocha A \& Sousa M 2010 Comparative ultrastructural analysis of diestrous and anestrous canine Grade 1 cumulus-oocyte complexes. Animal Reproduction Science 122 244-252. (doi:10.1016/j.anireprosci. 2010.08.018)

Lopes G, Alves MG, Carvalho RA, Luvoni GC \& Rocha A 2011 DNA fragmentation in canine oocytes after in vitro maturation in TCM-199 medium supplemented with different proteins. Theriogenology $\mathbf{7 6}$ 1304-1312. (doi:10.1016/j.theriogenology.2011.05.037)

Luvoni GC, Chigioni S, Allievi E \& Macis D 2005 Factors involved in vivo and in vitro maturation of canine oocytes. Theriogenology 63 41-59. (doi:10.1016/j.theriogenology.2004.03.004)

Marei WF, Wathes DC \& Fouladi-Nashta AA 2009 The effect of linolenic acid on bovine oocyte maturation and development. Biology of Reproduction 81 1064-1072. (doi:10.1095/biolreprod.109.076851)

Marei WF, Ghafari F \& Fouladi-Nashta AA 2012 Role of hyaluronic acid in maturation and further early embryo development of bovine oocytes. Theriogenology 78 670-677. (doi:10.1016/j.theriogenology. 2012.03.013)

Menezo Y, Dale B \& Cohen M 2010 DNA damage and repair in human oocytes and embryos: a review. Zygote 18 357-365. (doi:10.1017/ S0967199410000286) 
Nasr-Esfahani MH, Aitken JR \& Johnson MH 1990 Hydrogen peroxide levels in mouse oocytes and early cleavage stage embryos developed in vitro or in vivo. Development 109 501-507.

Natarajan R, Shankar MB \& Munuswamy D 2010 Effect of $\alpha$-tocopherol supplementation on in vitro maturation of sheep oocytes and in vitro development of preimplantation sheep embryos to the blastocyst stage. Journal of Assisted Reproduction and Genetics 27 483-490. (doi:10. 1007/s10815-010-9430-7)

Oh HJ, Fibrianto YH, Kim MK, Jang G, Hossein MS, Kim HJ, Kang SK, Lee BC \& Hwang WS 2005 Effects of canine serum collected from dogs at different estrous cycle stages on in vitro nuclear maturation of canine oocytes. Zygote 13 227-232. (doi:10.1017/S0967199405003242)

Otoi T, Fujii M, Tanaka M, Ooka A \& Suzuki T 1999 Effect of serum on the in vitro maturation of canine oocytes. Reproduction, Fertility, and Development 11 387-390. (doi:10.1071/RD00012)

Otoi T, Fujii M, Tanaka M, Ooka A \& Suzuki T 2000 Oocyte diameter in relation to meiotic competence and sperm penetration. Theriogenology 54 535-542. (doi:10.1016/S0093-691X(00)00368-X)

Otoi T, Ooka A, Murakami M, Karja NW \& Suzuki T 2001 Size distribution and meiotic competence of oocytes obtained from bitch ovaries at various stages of the oestrous cycle. Reproduction, Fertility, and Development 13 151-155. (doi:10.1071/RD00098)

Otoi T, Willingham L, Shin T, Kraemer DC \& Westhusin M 2002 Effects of oocyte culture density on meiotic competence of canine oocytes. Reproduction 124 775-781. (doi:10.1530/rep.0.1240775)

Otoi T, Shin T, Kraemer DC \& Westhusin ME 2007 Role of cumulus cells on in vitro maturation of canine oocytes. Reproduction in Domestic Animals 42 184-189. (doi:10.1111/j.1439-0531.2006.00750.x)

Qian Y, Shi WQ, Ding JT, Sha JH \& Fan BQ 2003 Predictive value of the area of expanded cumulus mass on development of porcine oocytes matured and fertilized in vitro. Journal of Reproduction and Development 49 167-174. (doi:10.1262/jrd.49.167)

Reynaud K, Saint-Dizier M \& Chastant-Maillard S 2004 In vitro maturation and fertilization of canine oocytes. Methods in Molecular Biology 253 255-272. (doi:10.1385/1-59259-744-0:255)

Reynaud K, Fontbonne A, Marseloo N, Thoumire S, Chebrout M, de Lesegno CV \& Chastant-Maillard S 2005 In vivo meiotic resumption, fertilization and early embryonic development in the bitch. Reproduction 130 193-201. (doi:10.1530/rep.1.00500)

Reynaud K, Fontbonne A, Marseloo N, Viaris de Lesegno C, Saint-Dizier M \& Chastant-Maillard S 2006 In vivo canine oocyte maturation, fertilization and early embryogenesis: a review. Theriogenology $\mathbf{6 6}$ 1685-1693. (doi:10.1016/j.theriogenology.2006.01.049)

Reynaud K, de Lesegno CV, Chebrout M, Thoumire S \& Chastant-Maillard S 2009 Follicle population, cumulus mucification, and oocyte chromatin configuration during the periovulatory period in the female dog. Theriogenology 72 1120-1131. (doi:10.1016/j.theriogenology.2009.07. 006)

Rodrigues BA \& Rodrigues JL 2010 In vitro maturation of canine oocytes: a unique conundrum. Animal Reproduction 7 3-15.
Rodrigues Bde A, dos Santos LC \& Rodrigues JL 2004 Embryonic development of in vitro matured and in vitro fertilized dog oocytes. Molecular Reproduction and Development 67 215-223. (doi:10.1002/ mrd.10394)

Rozen S \& Skaletsky H 2000 Primer3 on the WWW for general users and for biologist programmers. Methods in Molecular Biology 132 365-386. (doi:10.1385/1-59259-192-2:365)

Silva AE, Rodriguez P, Cavalcante LF, Rodrigues BA \& Rodrigues JL 2009 The influence of oxygen tension on cumulus cell viability of canine COCs matured in high-glucose medium. Reproduction in Domestic Animals 44 (Suppl 2) 259-262. (doi:10.1111/j.1439-0531. 2009.01406.x)

Song HJ, Kang EJ, Kim MJ, Ock SA, Jeon BG, Lee SL \& Rho GJ 2010 Influence of parthenogenetic activation on nuclear maturation of canine oocytes. Journal of Veterinary Medical Science 72 887-892. (doi:10. 1292/jvms.09-0563)

Songsasen N \& Wildt DE 2005 Size of the donor follicle, but not stage of reproductive cycle or seasonality, influences meiotic competency of selected domestic dog oocytes. Molecular Reproduction and Development 72 113-119. (doi:10.1002/mrd.20330)

Songsasen N \& Wildt DE 2007 Oocyte biology and challenges in developing in vitro maturation systems in the domestic dog. Animal Reproduction Science 98 2-22. (doi:10.1016/j.anireprosci.2006.10.004)

Songsasen N, Fickes A, Pukazhenthi BS \& Wildt DE 2009 Follicular morphology, oocyte diameter and localisation of fibroblast growth factors in the domestic dog ovary. Reproduction in Domestic Animals $4 \mathbf{4}$ (Suppl 2) 65-70. (doi:10.1111/j.1439-0531.2009.01424.x)

Tao Y, Chen H, Tian NN, Huo DT, Li G, Zhang YH, Liu Y, Fang FG, Ding JP \& Zhang XR 2010 Effects of L-ascorbic acid, $\boldsymbol{\alpha}$-tocopherol and co-culture on in vitro developmental potential of porcine cumulus cells free oocytes. Reproduction in Domestic Animals 45 19-25. (doi:10.1111/j. 1439-0531.2008.01129.x)

Tesoriero JV 1982 A morphologic, cytochemical, and chromatographic analysis of lipid yolk formation in the oocytes of the dog. Gamete Research 6 267-279. (doi:10.1002/mrd.1120060309)

Wakefield SL, Lane M, Schulz SJ, Hebart ML, Thompson JG \& Mitchell M 2008 Maternal supply of omega-3 polyunsaturated fatty acids alter mechanisms involved in oocyte and early embryo development in the mouse. American Journal of Physiology. Endocrinology and Metabolism 294 E425-E434. (doi:10.1152/ajpendo.00409.2007)

Whitaker BD \& Knight JW 2008 Mechanisms of oxidative stress in porcine oocytes and the role of anti-oxidants. Reproduction, Fertility, and Development 20 694-702. (doi:10.1071/RD08037)

Received 14 May 2012

First decision 29 June 2012

Revised manuscript received 31 August 2012

Accepted 6 September 2012 